\title{
MODERATING EFFECTS OF INTERVENTION PROGRAMS ON THE RELATIONSHIPS BETWEEN PSYCHOSOCIAL FACTORS AND THERAPEUTIC BEHAVIOR AMONG OBSTETRIC FISTULA PATIENTS IN NORTHERN NIGERIA: A PILOT STUDY
}

\author{
Faruk U. Abubakar \\ Department of Nursing Sciences, \\ Usmanu Danfodiyo University Sokoto, Nigeria
}

\begin{abstract}
The objective of this study was to assess a few sample data quantitatively, on the subject matter of moderating effects of intervention programs on the relationships between psychosocial factors and therapeutic behavior among obstetric fistula patients in northern Nigeria. The study employed a cross-sectional survey design, and utilized a simple random sampling technique to collect 100 properly filled questionnaires following perusal by the panel of experts. The questionnaires had high response rate of $87.8 \%$ because they were researcheradministered. Additionally, the study adapted 5 constructs in the framework. The data was analyzed with the SPSS quantitative analysis software v22. The results of the pilot study shows that all the constructs have a high-reliability values that ranged from 0.79 to 0.94 ; this is in line with the recommendations that a Cronbach's alpha coefficient threshold should be 0.70 or greater; indicating that the instrument possesses high reliability. Consequently, based on the foregoing values and meticulous scrutiny by the panel of experts, all the adapted constructs are reliable and valid.
\end{abstract}

Keywords-Moderating effects, Intervention programs, psychosocial factors, health-seeking behavior, pilot study

\section{INTRODUCTION}

Obstetric fistula is a medical condition whereby a hole develops in the birth canal mostly due to childbirth (Wall, 2012, \& FMOH, 2012). Specifically, the hole can be between the rectum and the vagina or the urinary bladder and the

\author{
Muhammad Anka Nasiru \\ Department of Nursing Sciences. \\ Usmanu Danfodiyo University Sokoto, Nigeria
}

vagina, which can lead to urine and or fecal incontinence (Wall, 2012 \& Siddle, Mwambingu, Malinga, \& Fiander 2013). The disease condition is characterized by social, physical, medical, and psychological features and consequences (Wall, 2012), Globally, the condition causes agony to an estimated 3 million women (Wall, 2012), with an annual prevalence rate estimated to be $85,000-100,000$ mostly in developing countries such as Nigeria (Wall, 2012 \& Odu, 2013).

In Nigeria, the victims of obstetric fistula are estimated to be about 700,000-1,000,000 (Wall, 2012), with almost 20,000 new cases of the disease arising year after year (FMOH, 2012 \& Wall, 2012). Northern Nigeria is the hardest hit by the disease condition, with an estimated 500,000750,000 cases of the ailment, which accounts for close to 70 percent of the total case of the illness in Nigeria $(\mathrm{FMOH}$, 2012). In addition, in northern Nigeria, an average of 2 to 5 cases of the disease occur in every 1,000 delivery compared to only 0.44 cases for each 1,000 delivery in Southern Nigeria (FMOH, 2012). More disturbing is that, in spite of the huge number of obstetric fistula patients in Nigeria, and particularly northern Nigeria, only an estimated 5,000 patients undergo repairs annually; this compound the disease profile in the country (FMOH, 2012).

Recently, a report from the Federal Ministry of Health, Nigeria indicated that, perhaps the failure of most areas in northern Nigeria to get rid of obstetric fistula may well be related to several reasons, including but not limited to inadequate training of health personnel, poor healthcare infrastructure, and lack of knowledge that the disease can be treated using modern healthcare system among others (FMOH, 2012 \& Wall, 2012). In addition, and more 


\section{International Journal of Engineering Applied Sciences and Technology, 2019 Vol. 4, Issue 8, ISSN No. 2455-2143, Pages 316-322 \\ Published Online December 2019 in IJEAST (http://www.ijeast.com)}

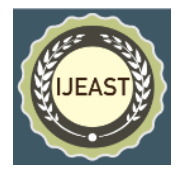

decisively, the disease may perhaps have persisted in northern Nigeria for the reason that greatest number of patients afflicted with the disease were not capable of trying to seek help from designated health centers, perhaps due to certain factors, including but are not limited to decision-making autonomy (FMOH, 2012, Wall, 2012 \&, Bleich et al. 2013), attitude of health personnel (Holmes \& Goldstein, 2012), and social support (Borgman \& Akin, 2012, \& Dunne, Fraser, \& Gardner 2014), On the other hand, other scholars (Bankole, 2009, Namasivayam, Osuvra, Syed, \& Antai 2012, Yadav, 2010, Mannara, Durrant, Fisher, Chersich, \& Luchters 2015, Afsana, \& Rashid 2017) argued, even when these elements mentioned in the preceding discussion are not favourable, so many patients seek for competent healthcare services.

Several studies have examined the influence of the selected psychosocial factors on therapeutic behavior, and have established some mixed findings. So for example, studies by Bleich, et al. (2013) and Namasivayam et al. (2012) concerning decision-making autonomy and therapeutic behavior among women in four countries; India, Nepal, Kenya and Namibia, and additional study in Nigeria have found inconsistent results. Furthermore, a study concerning attitudes of skilled staff midwives in private and government missionary hospitals in Oyo, Nigeria, reported inconsistent findings. Results show that there is a positive relationship between staff attitude at the private missionary hospital and women who go to the clinic for delivery. Similarly, studies by Borgman (2012) and Dunne et al. (2014) as regards to social support for women who visit the hospital for delivery, shows inconsistencies in their findings. Additionally, reports from the FMOH; (2012) indicated that previous intervention programs have not been effective; commensurate to the rates of the programs and high backlog of unrepaired VVF women and overall, the high number of existing cases in Nigeria.

Therefore, based on the inconsistencies among earlier studies, those have provided justification for the introduction of a moderator (Barron \& Tix 2004). A moderator is introduced if the relationship between predictor (independent variable) and an outcome (dependent variable) is inconsistent or weak. In addition and more importantly, Barron et al. (2004) recommends that a study can introduce an appropriate moderator if there is evidence that previous intervention program(s) have been weak or ineffective. Therefore, the above scenarios created a "gap" which is filled by this study through the introduction of a "moderator" to strengthen the rel ationship between transportation, stigma, quality of health and health-seeking behavior.

Therefore, based on the preceding discussion, this investigator was inspired to carry out a pilot study to assess the carefully chosen measuring instruments to establish their reliability and validity prior to the use of the instruments in the main study. Consequently, this study comprises of 5 major sections. The first section includes the introduction, followed by the literature review of the key constructs in section two. The third section discusses the research methodology, followed by the results of the pilot study in section four. Finally, the fifth section presented the conclusion and recommendations of the study.

\section{LITERATURE REVIEW}

\section{A. Therapeutic behavior}

Therapeutic behavior infers to activities that the individuals or group with certain health challenges engaged in to prevent illness, promote health, or cure certain illnesses (Akhter, 2015). Furthermore, therapeutic behavior entails action that involves commitments from the individuals who are facing apparent challenges, in that, the individuals ought to be ready to accept the fact that they desire to make progress or accept treatment for the illness affecting them, through the acceptance of orders from competent medical professionals, with a view to improving health (Behrami, Afashbahar, Shaka -hifa \& Montazeral, 2014). Generally, the construct represents a sick individual working together with other persons to acquire support, which could be in the form of information, therapy, and general support grounded on a particular problem a seeker brought with him (Akhter, 2015). This definition of therapeutic behavior by Akhter (2015) is an indication that health professionals, mainly those responsible for the care of obstetric fistula patients are beginning to appreciate the construct of 'therapeutic behavior' as an important part of their way of life. Additionally, Behrami, et al (2012) highlighted that the role of therapeutic behavior according to Woldeammanuel (2012) is imperative for the health personnel to understand various psychosocial factors, and more importantly the moderating factors which influence peoples' decision to seek therapy.

\section{B. Psychosocial Factors}

The term psychosocial factors imply to those psychological and social elements that can influence the therapeutic behavior of the individuals in the society (Furqan, Bismah \& David, 2012 \& Akhter, 2015). Furthermore, the concept is also defined as important one, which could positively influence people with certain challenges to participate in cure. According to Ramirez (2013), some of the most prominent perceived psychosocial factors that positively influence therapeutic behavior include but are not limited to decision-making, attitude of health professionals, and social support. Therefore, based on the numerous definitions of the concept of psychosocial factors influencing therapeutic behavior in the preceding discussion, this paper examined the influences the construct might have when combined with a moderator to motivate obstetric fistula patients to partake in therapy.

\section{B. I Decision-making Autonomy}

Decision-making refers to a situation where women and men have relatively equal chances in engagement into 


\section{International Journal of Engineering Applied Sciences and Technology, 2019 Vol. 4, Issue 8, ISSN No. 2455-2143, Pages 316-322 \\ Published Online December 2019 in IJEAST (http://www.ijeast.com)}

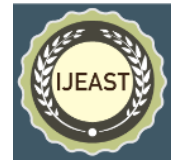

discussions concerning matters affecting them and the family (Bleich, Jarlenski, Bell \& Laveist 2012 \& Namasivayam, Osuvra, Syed \& Antai 2012). According to Namasivayan, et al. (2012) and Bleich, et al. (2012), the participation of women in decision-making has a remarkable advantage, in that, in a society where women participate in important decisions affecting their lives and families; there are high chances of improving the health and economy of that society. Conversely, lack of decision-making power available to women may result in the violation of their rights to health and other fundamental human rights (Bankole, 2009). Several studies by Bankole, (2009) and Namasivayam et al. (2012) have examined the influence of decision-making on the therapeutic behavior of sick individuals and have established some inconsistencies. So for example, Bankole (2009) reported that in Nigeria, only 1012 percent of women in northern Nigeria participate in decision-making affecting their health, compared to 50 percent in southern Nigeria. In addition, Namasivayam et al. (2012) reported mixed findings in studies of decision-making in four countries, which reveals women in India and Nepal possessed decision-making power to seek treatment. Conversely, in Kenya and Namibia, the study shows a majority of women in rural communities do not have decision-making power; which affects their participation in seeking health care services.

In line with the preceding studies, Bleich et al. (2013) in his examination of decision-making as a factor inhibiting seeking healthcare services suggested further studies to focus on how problem of decision-making affects participation in health programs in other social context, as well as to evaluate the development in health inequalities in such new environments. Again, the majority of the studies employed either qualitative or quantitative methods alone to examine decision-making, which creates a methodological gap that may well be filled using mixed method research design (Sekaran, \& Bougie, 2013).

Thus, this study tested the reliability and validity of the construct, decision-making, which will be used in both the direct and the indirect relationships in the main study.

\section{B. II Attitude of Health Personnel}

The term attitude of health personnel signifies the behavior of the health workers exhibited towards the patients; the behavior could be positive or negative. The positive behavior of the health care personnel includes showing to the patients' kindness, respect, and politeness among others in the course of therapy (Holmes \& Goldstein, 2012). Conversely, the negative attitude of health personnel is shown to the patient by way of verbal abuse, disrespect, showing lack of empathy and sympathy, physical assault, and poor attention to confidentiality among others (Furqan, Bismah, \& David, 2012). In addition, Holmes, et al. (2012) contends that the construct of the attitude of health personnel involves relating with the patients through being friendly, respectful, and polite among others. On the other hand, the concepts involve behaving negatively towards the patients in a manner that depict staff as being cruel, abusive, rude and staff discharging their duties without fairness (Holmes, et al. 2012).. The attitude of health personnel as a concept is important because a positive attitude helps to promote interpersonal communication between the patient and the healthcare providers; this ultimately helps to offer quality health care services to the patients (Holmes, et al. 2012). On the other hand, the negative attitudes of health personnel create an unhealthy gap and barrier to seeking treatment (Holmes, et al. 2012).

Several studies concerning the attitude of health personnel reported some inconsistencies in their result. So for example, a study by Furqan et al. (2012) indicated that staff's negative attitude lowered the participation of pregnant women in treatment in rural Pakistan. Conversely, a study in some selected Zambian hospitals utilizing 86 sampled women for antenatal care, labor and those undergoing abortion indicated that the attitude of most of the healthcare providers in the area is positive (Mannara, Durrant, Fisher, Chersich, \& Luchters 2015). In addition, a study in Bangladesh suggests that health personnells attitude is good because the workers continually assess the health conditions of the sick in the hospital; they serve medication at the right time and sometimes offer financial assistance to the clients (Afsana, \& Rashid 2017). Furthermore, a study in four South African regions using 187 respondents reported that over 65 percent of the respondents reported that they visit the antenatal care unit to seek for treatment because the health workers are friendly (Tlebere, Jackson, Loveday, Matizinta, Mbombo, Doherty, Chopra, 2007). Additionally, a study in the Ashanti region in Ghana hospitals suggests that health workers providing HIV/AIDS services to clients demonstrated positive attitude and behaviors, in that, health personnel received patients into the center warmly, speak to the patients with respect, advice patients on several issues, and they offer financial help to the patients (Jonathan, 2016).

Based on the foregoing discussion, the reviewed literature offered some gaps for further study. First, the analysis of the concept of the attitude of health personnel by the previous studies was mostly qualitative driven, which emphasizes on understanding the lived experiences of the participants; as such the studies cannot be generalized to the universe, this assumption is in line with the views of Pearce (2012). In relation to the preceding discussion, Furqan, et al. (2012) suggested further studies to focus on examining attitudes of health personnel through the use of surveys and interview concurrently. In addition, most of the studies on the attitude of health professionals for example, were conducted in Bangladesh, Ghana, South Africa, Zambia, Pakistan and Europe. These countries are different from Nigeria in terms of culture and environment. For that reason, this study will assess the construct in a new social context among obstetric fistula patients in northern Nigeria. Similarly, most of the studies on the attitude of health personnel applied the concept to study diseases and problems such as abortions, antenatal and 


\section{International Journal of Engineering Applied Sciences and Technology, 2019 Vol. 4, Issue 8, ISSN No. 2455-2143, Pages 316-322 \\ Published Online December 2019 in IJEAST (http://www.ijeast.com)}

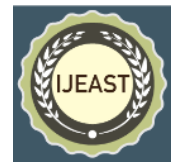

postnatal care, HIV/AIDS among others. Then, this study examined the concept in relation to obstetric fistula. In addition and more importantly, the inconsistencies or mixed findings among previous studies that examined the construct of the attitude of health personnel provided justification for the introduction of moderating variables, which is in line with the opinions of Barron et al (2004). Thus, this study introduced intervention programs as an appropriate moderating variable to strengthen the relationship between the attitude of health personnel and therapeutic behavior of obstetric fistula patients, which is in line with the views of Bellows et al. (2014). Consequently, this study tested the reliability and validity of the construct, attitude of health personnel, which will be used in both the direct and the indirect relationships in the main study.

\section{B.III Social support:}

Social support refers to the concrete and emotional support offered to an individual by the members of one's family, friends and community among others (Yadav, 2010 \& Upton \& Upton, 2015). Dunne, et al. (2014) stated that social support is significant, in that support from family, relatives, friends among others enhance satisfaction and psychosocial wellbeing. The same scholar maintained that support from the loved ones is even more important among women who are about to deliver in the health centers, in which the presence of their loved ones could boost the confidence and comfort of a woman, leading to reduce patient's anxiety. Conversely, lack of social support from friends, family and community may lower an individual's level of confidence as well as cause damage further damage to the physical and psychological well-being of the patient (Yadav, 2010).

Several studies have examined social support in relation to therapeutic behavior among patients receiving treatment and the results showed some inconsistencies. So, for example, a study by Borgman et al. (2012) on social support, gender, and treatment-seeking behavior for substance abuse found a significant positive relationship between social support through the company of significant others and seeking treatment. Conversely, Dunne, et al (2014) found negative relationship between social support through multiple companies of significant others and treatment-seeking intention. Dunne et al (2014) further argued that even where the relatives of a pregnant woman accompanies her to the health center for delivery, the health personnel could prevent the patient's relatives from staying in the ward. In some cases, nurses or ward in-charges may ask patients' relatives to leave, in this case, the woman feels uncomfortable, thereby eroding the sense of social support (Dunne, et al 2014). In line with the preceding discussion, Borgman et al. (2012) suggested further studies that could add new sources of social support to the existing old ones, including examining support from the religious organizations, employers, philanthropist, and club support groups.
Furthermore, the inconsistencies or mixed findings among previous studies that examined social support offered justification for the introduction of moderating variable, which is in line with the opinions of Barron et al. (2004). Thus, this study introduced intervention programs as an appropriate moderating variable to strengthen the relationships between social support and therapeutic behavior of obstetric fistula patients, which is in line with the views of Bellows et al. (2014). Consequently, this study will examine the construct in the direct relationships and the indirect relationships among patients with obstetric fistula.

\section{B.IV Intervention Programs}

The intervention programs refer to the mixture of plans (social, economic, and health among others) designed to produce positive changes in the behavior of people or cause an improvement of peoples' health (FMOH, 2012). According to the Federal Ministry of Health (FMOH, 2012), several governmental and non-governmental programs exist in developing societies, aimed to encourage people, particularly women to partake in cure just as some of these programs were employed in advanced societies in the eradication of illnesses. However, Bellow et al. (2014) indicated that, in spite of several efforts made by the government through various intervention programs to eradicate preventable diseases, the prevalence rate of the ailments remains high, perhaps because previous programs have not yielded desired results. Thus, because of the ineffectiveness of previous intervention programs in influencing women towards treatment-seeking, Bellows, et al. (2014) suggested for the inclusion of appropriate intervention programs such as awareness campaign through the radio and educational pamphlets to motivate women to seek therapy. Second, the previous study suggested the effective documentation of the programs implemented for removing both demand (psychosocially based) and supply (hospital facility-based) aspects of factors that could hold back individuals of reproductive age from looking out for healthcare services.

Therefore, in line with the inconsistencies among the psychosocial construct, which result to the introduction of the suitable moderator, intervention programs, it has become pertinent to test the reliability and the validity of the instruments to ensure that they are not only error-free, consistent and constant across several items of the scales but also the instruments are evaluating what they are supposed to measure. Based on this reason, this study presents the findings of the pilot study concerning the moderating effects of intervention programs on the relationships between psychosocial factors and therapeutic behavior of obstetric fistula patients in northern Nigeria.

\section{METHODOLOGY}

This study focuses on a pilot study so that this investigator can clear doubts concerning the validity and the reliability of the measuring tools utilized by this paper. 


\section{International Journal of Engineering Applied Sciences and Technology, 2019 Vol. 4, Issue 8, ISSN No. 2455-2143, Pages 316-322 \\ Published Online December 2019 in IJEAST (http://www.ijeast.com)}

Moreover, the outcome of the pilot study will be incorporated in the main study, and perhaps perform a review of the measuring instruments where necessary, this is in line with the endorsement of Neuman (2006). Therefore, a cross-sectional survey research design was adapted in this study to assess the perceptions of obstetric fistula patients in northern Nigeria, which is in accordance with the opinions of Neuman (2006). In a pilot study, the sample used is usually small (Neuman, 2006), nevertheless, it is usual to increase the sample size to just about 100 respondents (Neuman, 2006). So, in this study, a total of 115 questionnaires were administered by the researcher randomly.

The justification for the use of the researcheradministered questionnaire in this study is because the instrument permits researchers to gather data within a short period. Again, the instrument eliminates stress on the part of the participants, and the method guarantee that no contradictions are visible in the research findings. Another advantage of a researcher-administered questionnaire is it provides a high response rate because the questionnaires are gathered instantly; the researcher filled-in the answer he asked the respondents.

This study used a closed-ended questionnaire because it provides superior supports over other instruments such as ease of coding, tabularization, and helps respondents in making a quick choice which is easier for the researcher to code for onward analysis (Neuman, 2006). Additionally, items of the questionnaires were measured on five Likert-scales. Out of the 115 questionnaires administered by the researcher, 100 questionnaires were correctly completed, while 15 questionnaires have not been correctly filled, as such only 100 were used for the analysis. The high response rate of $87.8 \%$ was attained largely because the questionnaires were researcher-administered (the researcher tick responses selected by respondents).

Table 1: Measurement Instruments and Sources

\begin{tabular}{|c|c|c|c|}
\hline & Instrument & Sources & Items \\
\hline 1. & $\begin{array}{c}\text { Decision-making } \\
\text { Autonomy }\end{array}$ & $\begin{array}{c}\text { Namasivayam et al. (2012) and } \\
\text { Bleich, et al.(2013) }\end{array}$ & 8 \\
\hline 2. & $\begin{array}{c}\text { Attitude of Health } \\
\text { Personnel }\end{array}$ & $\begin{array}{c}\text { Holmes et al. (2012) and } \\
\text { Bourquine et al. (2015) }\end{array}$ & 12 \\
\hline 3. & Social Support & Dunne et al. (2014) & 8 \\
\hline 4. & Therapeutic Behaviour & Behrami, et al. (2014) & 14 \\
\hline 5. & Intervention Programs & Keating et al. (2006) & 15 \\
\hline & Total & & 57 \\
\hline
\end{tabular}

This study consist of five (5) constructs as indicated in Table 1 , namely decision-making autonomy, the attitude of health personnel, social support, and intervention programs, which are the independent variables, while, therapeutic behavior is the dependent variable. The construct of decision-making autonomy employed in this study has 8 items, which were adapted from the original work of Namasivayam et al. (2012) and Bleich et al (2012). Additionally, the construct of attitude of health personnel consists of 12 items adapted from the original work of Holmes et al. (2012) and Bourquine et al. (2015). Moreover, the construct of social support modified in this study consists of 8 items from the original work of Dunne, et al. (2014). Similarly, the construct of therapeutic behavior consists of 14 items, which were adapted from the original work of Behrami, et al. (2014). Lastly, the construct of intervention programs consists of 15 items, which was modified in this study from the original work of Keating et al. (2006).

\section{RESULTS}

\section{A. Validity Test}

Validity test shows the evidence that instruments utilized in a particular study are appropriate in measuring the proposed research constructs (Neuman, 2006). In this study, content or face validity was employed to ensure that the items are valid and that they are measuring the construct, this is in line with the opinions of Neuman (2014). In this study, the panel of experts and a small sample size of 115 respondents were asked to offer comments and give feedback on the relevance of the items adapted to measure constructs. The experts contacted consist of health professionals from Usmanu Danfodiyo University Teaching Hospital, Sokoto, and Maryam Abacha Women and Children Hospital, Sokoto among others were referred to test the unambiguousness of the survey instruments.

Moreover, the instruments were administered to some obstetric fistula patients for their feedback. After the feedback from the experts and the patients, some items were re-phrased suitably to measure the construct as well as for easy comprehension by respondents in the main study.

\section{B. Reliability Test}

The reliability test points out the extent to which respondents' answers to the entire questions employed in a study are consistent (Neuman, 2006). Consequently, this study utilized SPSS software to test for reliability. Out of the numerous existing statistical techniques for measuring reliability, Cronbach's alpha coefficient was utilized, in line with the recommendation made by Neuman (2006).

From the result of reliability test in Table 2 , it has been confirmed that all the five (5) constructs have a highreliability values that ranged from 0.79 to 0.94 ; this is in line with the recommendations of Neuman (2006) that a Cronbach's alpha coefficient threshold should be 0.70 or greater indicating that the instrument possesses high reliability. Table 2 shows a summary of the reliability results. Based on the result, it is obvious that the pilot study had shown the Cronbach's alpha values of the five (5) distinct constructs under study that have exceeded 0.70 . Therefore, based on the recognized benchmark of 0.70 , it can be concluded that the entire constructs are reliable; so, there was no need to get rid of any item. 


\section{International Journal of Engineering Applied Sciences and Technology, 2019 Vol. 4, Issue 8, ISSN No. 2455-2143, Pages 316-322 \\ Published Online December 2019 in IJEAST (http://www.ijeast.com)}

Table 2: Reliability Test Result

\begin{tabular}{|c|c|c|c|}
\hline S/N & Construct & $\begin{array}{c}\text { No. of } \\
\text { Items }\end{array}$ & Cronbach's Alpha \\
\hline 1. & Decision-making Autonomy & 8 & .79 \\
\hline 2. & Attitude of Health Personnel & 12 & .81 \\
\hline 3. & Social Support & 8 & .80 \\
\hline 4. & Therapeutic Behaviour & 14 & .92 \\
\hline 5. & Intervention Programs & 15 & .94 \\
\hline
\end{tabular}

Additionally, Table 3 indicates the descriptive analysis of the respondent's characteristics. Concerning the educational level of the respondents, Table 3 indicates that 93 (93\%) who are the majority do not possess formal education, while the least 1 (1\%) have secondary school education and $1(1 \%)$ did not graduate, respectively. This implies that the bulks of the respondents are not literate.

Table 3: Characteristics of Respondents

\begin{tabular}{|c|c|c|c|}
\hline Demographic Variable & Categories & Frequency & $\begin{array}{c}\text { Percentage } \\
(\%)\end{array}$ \\
\hline \multirow[t]{4}{*}{ Educational Level } & No formal education & 93 & 93.0 \\
\hline & Primary School & 5 & 5.0 \\
\hline & Secondary School & 1 & 1.0 \\
\hline & Did not Graduate & 1 & 1.0 \\
\hline Total & & 100 & 100.0 \\
\hline \multirow[t]{3}{*}{ Occupation } & Employed & 1 & 1.0 \\
\hline & Unemployed & 95 & 95.0 \\
\hline & House-wife & 4 & 4.0 \\
\hline Total & & 100 & 100.0 \\
\hline \multirow[t]{3}{*}{ Income per month } & Less than N3000 & 93 & 93.0 \\
\hline & N7000-N10000 & 6 & 6.0 \\
\hline & Above N11000 & 1 & 1.0 \\
\hline Total & & 100 & 100.0 \\
\hline \multirow{2}{*}{ Repairs } & Yes & 62 & 62.0 \\
\hline & No & 38 & 38.0 \\
\hline Total & & 100 & 100.0 \\
\hline \multirow{2}{*}{ Awareness Campaign } & Yes & 87 & 87.0 \\
\hline & No & 13 & 13.0 \\
\hline Total & & 100 & 100 \\
\hline \multirow[t]{2}{*}{ Help } & Yes & 69. & 69.0 \\
\hline & No & 31 & 31.0 \\
\hline Total & & 100 & 100.0 \\
\hline \multirow{2}{*}{ Teaching } & Yes & 79 & 79.0 \\
\hline & No & 21 & 21.0 \\
\hline Total & & 100 & 100.0 \\
\hline \multirow[t]{2}{*}{ Advice } & Yes & 88 & 88.0 \\
\hline & No & 12 & 12.0 \\
\hline Total & & 100 & 100.0 \\
\hline
\end{tabular}

In addition, concerning the employment status of the respondents, Table 3 shows that the majority of the respondent $95(95 \%)$ are unemployed, while the least, $1(1 \%)$ of the respondents are employed. Furthermore, concerning intervention programs, specifically repairs, the majority 62 (62\%) had fistula surgical repairs, while the least, 38 (38.0\%) were not repaired. Additionally, the majority of the respondents $87(87 \%)$ participated in therapy due to awareness campaigns from the radio, while the least, 13 (13\%) participated in cure due to referral by other sources, such as previous obstetric fistula patients. Again, concerning help offered to women for skills acquisition, the majority of the respondents, $69(69 \%)$ reported that they received training, while the least, 31 (31\%) did not receive training. Similarly, with regards to health teaching, the majority of the respondents, $79(79 \%)$ partake in teaching, while the least, 21 $(21 \%)$ did not take part in teaching. Furthermore, concerning advice offered to patients, the majority $88(88 \%)$ of the respondents reported been counseled, while the least $12(12 \%)$ were not counseled. This result indicated that the majority of the obstetric fistula patients have taken part in intervention programs. Thus, by implication, it shows that perhaps in the main study, intervention programs might be an important factor in influencing participation in therapy among obstetric fistula patients.

\section{DISCUSSION, CONCLUSION, AND LIMITATION}

The fundamental objective of this study was to test the reliability and validity of the measuring instruments of the selected constructs to ensure that the tools are error-free before utilizing the items in the main study. As a result, judging from the preceding specified objective, the results of the study have achieved its overall goal. Specifically, the validity of the instruments was achieved because the study's respondents have proven a good understanding of the questions that they were asked. The preceding scenario was made possible because of the powerful inspection of the designed questionnaire by the panel of experts and the initial responses gathered from the 100 respondents in the pilot study. Similarly, the reliability of the instruments was confirmed utilizing the Cronbach's alpha coefficient. The result of the reliability test indicated that the entire study constructs are above the benchmark of 0.70 . Evolving from the preceding result, it can be concluded that the reliability and validity of the study's instruments have been attained, and the items are secure to be utilized in the main study. This study has some limitations, in that; significant amount of time than the normal 20-30 minutes was spent by this researcher in making effort to translate to the majority of respondents the researcheradministered questionnaire that was designed in the English language to the local language (Hausa Language). Consequently, due to the identified weakness in the pilot testing, this study recommends for employing the services of a qualified translator to translate the researcher-administered questionnaire developed in the English language to the Hausa language to facilitate data collection in the main study,

\section{REFERENCES}




\section{International Journal of Engineering Applied Sciences and Technology, 2019 \\ Vol. 4, Issue 8, ISSN No. 2455-2143, Pages 316-322 \\ Published Online December 2019 in IJEAST (http://www.ijeast.com)}

[1] Afsana, K., \& Rashid, S (2017). The challenges of meeting rural Bangladeshi |women's need in delivery care. Reproductive health care matters. (pp. 79-89)

[2] Akhter, S. (2015). Maternal health care seeking behavior of women from lower and socio economic groups of Dhaka, Bangladesh-fear or fusion? Doctoral (PhD) dissertation thesis. (pp. 22-51).

[3] Bankole, A. Glida S., Friday, O., Collins I. \& Rubina, H. (2009) Barrier to safe motherhood in Nigeria, Guttmacher institute. New York. (pp 115-128)

[4] Behrami, M. A., Afashbahar, O., Shakahifar, M. \& Montazeral, F. R. (2014). Developing a valid tool of treatment seeking behavior survey for Iran. Journal of novel applied sciences. (pp. 651-660).

[5] Bellows, B., Bach, R., Baker, Z. \& Warren, C (2014) Barriers to obstetric fistula treatment in low-income countries: A systematic review, Population council. (pp. 1-6)

[6] Bleich, S. N., Jarlenski, M. P., Bell, C. N., \& Laveist, T. A. (2013). Health inequalities:Trend, progress, and policy. Annu Rev public health, (pp. 7-40).

[7] Boquiren, V. M, hack, T. F, Beaver, K. \& Williamson, S. (2015). What do measures of patient satisfaction with doctor tell us? Journal of patient education and counseling xxx, (pp. 1-9).

[8] Borgman, R. \& Akin, J. (2012). Social support, gender, and treatment-seeking behavior for substance abuse: does social support influence treatment attendance among substance abusing women and men. Discovery; Georgia state honors college undergraduate research journal. (pp. 335-351)

[9] Dunne, C. L., Fraser, J., \& Gardner, G. E. (2014). Women's perceptions of social support during labor: development, reliability and validity of the birth companion support questionnaire. Journal of midwifery (pp. 1-6)

[10] Federal Ministry of Health (2011). National Strategic Framework for the Elimination of Obstetric fistula in Nigeria, 2011-2015. (pp. 7-20).

[11] Barron, K. E. \& Tix, A. P. (2004) Testing moderator and mediator effects in counselling psychology research. Journal of counselling psychology. (pp. 115-134)

[12] Furqan, B. I., Bismah, B. I., \& David, A. S. (2012) Barriers to accessing surgical care in Pakistan: Healthcare barriers model and quantitative systematic review. Journal of surgical research, (pp. 84-94).

[13] Holmes, W. \& Goldstein, M. (2012). "Being treated like a human being": Attitudes and behaviors of reproductive and maternal health care providers. (pp.18-28)

[14] Keating, J. Meakers, D. \& Adeniyi, A. (2006) Assessing effects of media campaign on HIV/AIDS awareness and prevention in Nigeria: results from the vision project. Biomed central, (pp. 114-125).
[15] Mannava, P., Durrant, K., Fisher, J., Chersich, M. \& Luchters, S. (2015) Attitudes and behaviors of maternal health care providers in interactions with clients: a systematic review. Globalization and health. (pp. 1-17)

[16] Namasivayam, A., Osuvra, D. C., Syed, R. \& Antai, D. (2012). The role of gender inequities in women's access to reproductive health care: a population-level study of Namibia, Kenya, Nepal, and India. International journal of women's health, (pp. 351364).

[17] Neuman, L. W. (2006) Social research methods: qualitative and quantitative approaches. Boston, Pearson educational incorporation. (pp. 115-129)

[18] Pearce, L. D. (2012) Mixed methods inquiry in sociology.American journal of behavioural sociology (pp. 829-848)

[19] Siddle, K., Mwambingu, S., Malinga, T. \& Fiander, (2013). A. Psychosocial impact of obstetric fistula in women presenting for surgical care in Tanzania. International gyenecol journal. (pp. 1215-1220).

[20] Tlebere, P., Jackson, D., Loveday, M., Matizinta, L., Mbombo, N., Doherty, T...\& Chopra, M. (2007). Community-based satisfaction analysis of maternal and neonatal care in South Africa to explore factors that impact utilization of maternal health services. Journal of midwifery women's health, (pp. 342-35).

[21] Upton, D. \& Upton, P. (2015). Friends, and social support: psychology of wound healing. (pp. 65=79)

[22] Yadav S, (2019). Perceived social support, hope, and quality of life of person living with HIV/AIDS: a case study from Nepal. Quality of life research. (pp. 22-31). 